\title{
Simulation of Temperature Changes in Surrounding Rock during Hot Dry Rock Reservoir Exploitation
}

\author{
Xia Zhao \\ College of Geo-exploration Science and Technology, \\ Jilin University, \\ Changchun, 130026, China \\ e-mail: 362336620@163.com \\ Chen Xiong \\ College of Geo-exploration Science and Technology, \\ Jilin University, \\ Changchun, 130026, China \\ e-mail: chen1926@qq.com \\ Guo Liangliang \\ College of Construction Engineering, \\ Jilin University, \\ Changchun, 130026, China

\section{Xi Jianjun} \\ College of Geo-exploration Science and Technology, \\ Jilin University, \\ Changchun, 130026, China \\ Hebei Electric Power Design \& Research Institute, \\ Hebei Shijiazhuang, 050031, China
}

\author{
Zeng Zhaofa \\ College of Geo-exploration Science and Technology, \\ Jilin University, \\ Changchun, 130026, China
}

\section{Li Jing}

College of Geo-exploration Science and Technology, Jilin University, Changchun, 130026, China

\section{Wang Kun}

College of Geo-exploration Science and Technology, Jilin University, Changchun, 130026, China

\author{
Zhang Yanjun \\ College of Construction Engineering, \\ Jilin University, \\ Changchun, 130026, China
}

\begin{abstract}
In order to get the change of surrounding rock temperature during hot dry rock reservoir productive process, we used the Transport of Unsaturated Groundwater and Heat (TOUGH2) software to simulate the model which attached surrounding rock to hot dry rock (HDR) reservoir. On the condition that we set actual production and reservoir parameters to the model, we calculated change of reservoir temperature and surrounding rock while the HDR reservoir exploitation within 20 years. The result shows that the temperature of surrounding rock which is more than $100 \mathrm{~m}$ away from injection well almost will not be changed.
\end{abstract}

Keywords- hot dry rock; surrounding rock temperature; TOUGH2; hot dry rock exploitation

\section{INTRODUCTION}

As we all known, the world's energy shortage problem is more and more serious, and environmental problems of traditional energy sources is becoming more and more serious. Therefore, the task of developing new alternative energy becomes more and more urgent. Now new energy includes solar energy, hydropower, wind energy and tidal energy, biomass, nuclear energy, geothermal energy and so on. As a new clean energy, geothermal energy is paid attention to by the people day by day [1-3].

Hot dry rock (HDR) is a very important part of geothermal energy, so called the enhanced geothermal systems (EGS). It is characterized by large storage of heat, usually $3 \sim 10 \mathrm{~km}$ depth. Its temperature range is very wide, between $150 \sim 650{ }^{\circ} \mathrm{C}[4]$.

The reliability of the numerical simulation results mostly depends on the understanding of basic properties of rock mass and the reasonable simplification of various geological factors. In the development process of the numerical simulation of hot dry rock reservoir area, the software which is most widely used and successful is TOUGH series [5-10].

During the simulation of hot dry rock reservoir development, previous researchers rarely consider the 
influence of the surrounding rock. It is not enough that only the reservoir internal changes are considered. On the condition of surrounding rock, this paper simulated the productive process of hot dry rock, in order to get the influence range of surrounding rock during hot dry rock exploited.

\section{MODEL DESIGN}

In order to simplify the problem, the simple model is established. We put forward a series of assumptions as follows:

(1) Surrounding rock is granite rock, with low porosity and no water inside, electrical parameters is isotropic;

(2) The specific heat and heat conduction coefficient of surrounding rock and groundwater do not vary with temperature and pressure changes;

(3) Don't consider the water volume change with the temperature and pressure (water density is constant, and volume remains the same);

(4) Fracture only exists in reservoir area, so we used the equivalent medium in simulation calculation;
(5) Fluid recovery rate is $100 \%$, (there is no water loss in productive process);

(6) Ignore heat production due to the flow friction of water and rock fractures wall (there is no new heat generated in the rock mass).

We establish a two-dimensional model with reference of article [11], and carry on simulation calculation. To simulate the influence of the temperature of the surrounding rock with reservoir exploited, reservoir is set as $400 \mathrm{~m} * 400 \mathrm{~m}$, with $100 \mathrm{~m}$ range of surrounding rock, as shown in Fig .1, transverse model of the whole area is $600 \mathrm{~m}$ long, vertical depth is $600 \mathrm{~m}$. Model is divided into three areas: the peripheral area (surrounding rock) width is $10 \mathrm{~m}$ grid; near-well block grid width is $3 \mathrm{~m}$; inner reservoir area grid width is $5 \mathrm{~m}$. Injection Well is located in $(102,-1998)$, and Production Well is located in (498,-1602).

The fractured porous reservoir locates within $-1600 \mathrm{~m}$ to $-2000 \mathrm{~m}$ in the vertical and $100 \mathrm{~m}$ to $500 \mathrm{~m}$ in the $\mathrm{x}$ direction, with higher permeability. Outside surrounding rock have the range of $100 \mathrm{~m}$ thickness, with an extremely low permeability.
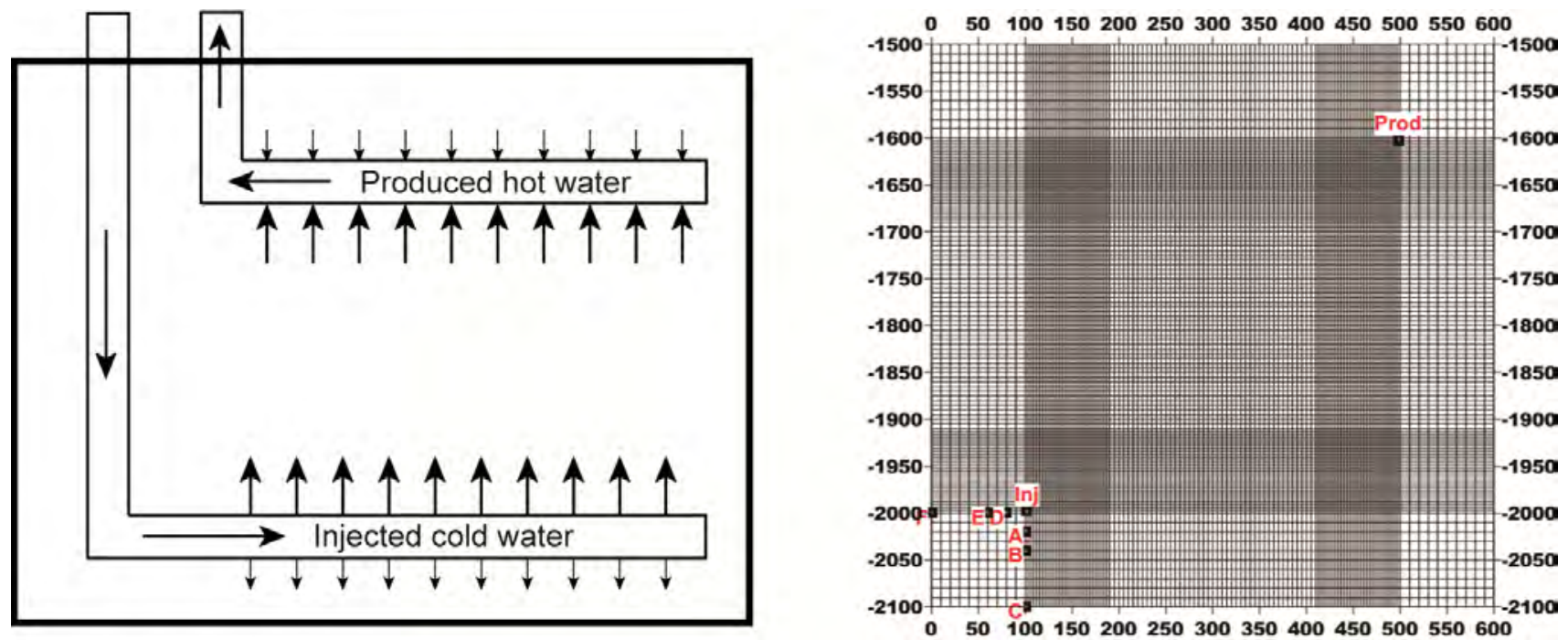

Figure 1. Idealized view of reservoir model of hot dry rock (HDR)

\section{MATHEMATICAL EQUATIONS}

\subsection{Heat transfer equation [12-15]}

In two-dimensional medium, heat transfer equation derivation is acquired based on the law of conservation of energy

$Q+\lambda\left(\frac{\partial^{2} T}{\partial x^{2}}+\frac{\partial^{2} T}{\partial y^{2}}\right)-\nabla \mathrm{g}\left(c_{w} \rho_{w} T_{w} \stackrel{\mathrm{r}}{v}\right)=\rho c \frac{\partial T}{\partial t}$

Eq. (1) is temperature field differential equation which includes heat source, heat conduction and heat convection. Its initial conditions is that initial temperature is set, when $t=t_{0}$,

$$
\left.T\right|_{t=t_{0}}=T_{0}=200 \quad \in S
$$

Boundary is adiabatic, so

$$
\lambda \frac{\partial T}{\partial n}=0
$$


$\frac{d}{d t} \int_{V n} M^{\kappa} d V=\int_{\Gamma n} F^{\kappa} g n d \Gamma+\int_{V n} q^{\kappa} d V$

Where, integral domain $V n$ represents an arbitrary volume. $M, F$ and $q$, respectively represents the quality, flux and source/sink of a material or component.

\subsection{Model thermal parameters}

Model parameters are set in table 1:

TABLE 1 MODEL PARAMETERS [11]

\begin{tabular}{|l|l|}
\hline parameters & value \\
\hline
\end{tabular}

\begin{tabular}{|c|c|}
\hline Rock density & $2850 \mathrm{~kg}^{*} \mathrm{~m}^{-3}$ \\
Rock specific heat & $1100 \mathrm{~J}^{*} \mathrm{~kg}^{-1} * \mathrm{~K}^{-1}$ \\
Rock thermal conductivity & $2.395 \mathrm{~W}^{*} \mathrm{~m}^{-1} * \mathrm{~K}^{-1}$ \\
Reservoir porosity & $2 \%$ \\
Reservoir permeability & $50^{*} 10^{-15} \mathrm{~m}^{2}$ \\
Initial temperature & $200^{\circ} \mathrm{C}$ \\
Injection rate & $1.5 \mathrm{~kg} / \mathrm{s}$ \\
Injection specific enthalpy & $262.12 \mathrm{~kJ} / \mathrm{kg}\left(\mathrm{about} 60^{\circ}\right)$ \\
Productivity index & $5.0^{*} 10^{-12} \mathrm{~m}^{3}$ \\
Production flow pressure & $5 \mathrm{MPa}$ \\
Injection flow pressure & $12 \mathrm{MPa}$ \\
\hline
\end{tabular}

IV.SIMULATION RESULTS
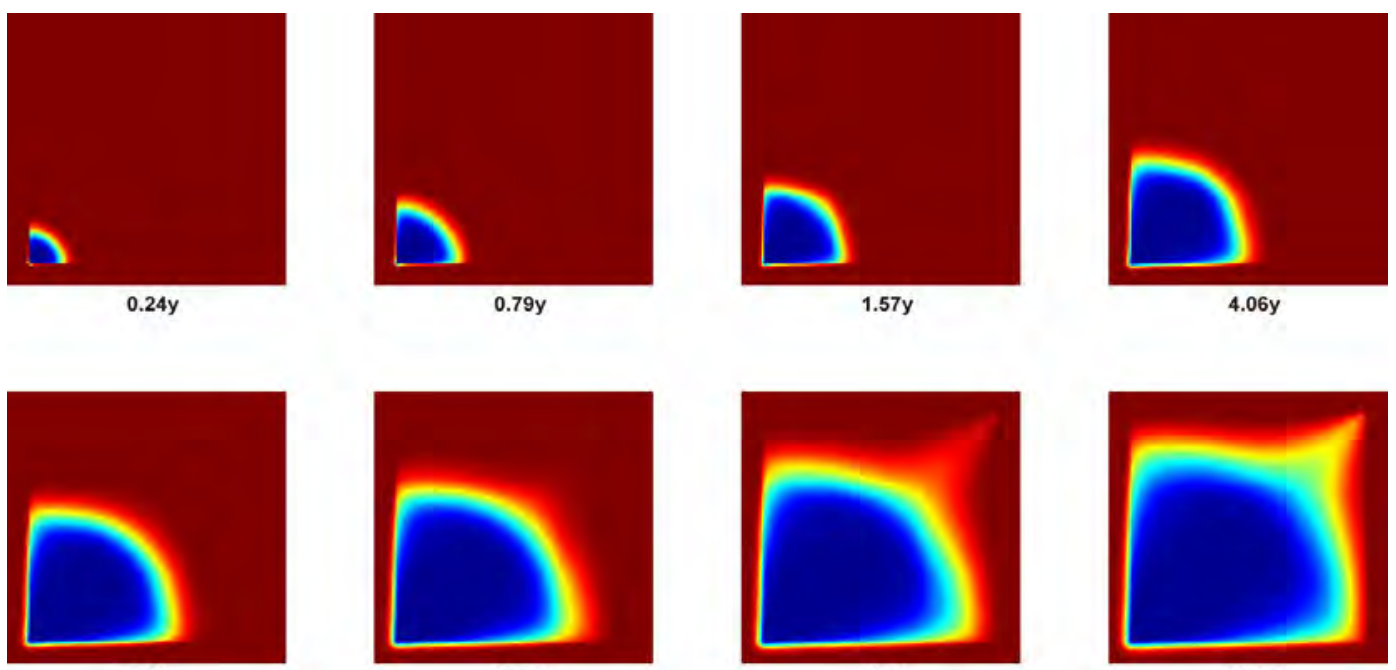

$11.75 y$

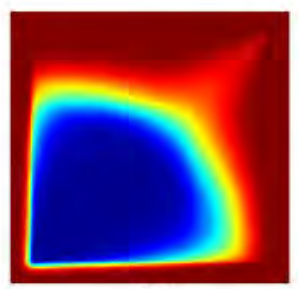

$15.90 y$

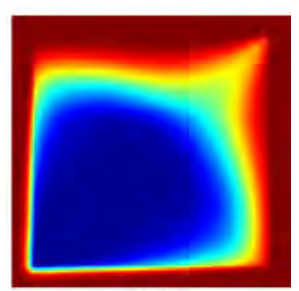

$20.01 y$

200

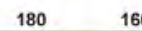
140 120 100 80

Figure 2. Distribution of reservoir and surrounding rock temperature during the 20 year period

Fig .2 shows changes of reservoir temperature in the productive process within 20 years. Though the figure we know that, at the beginning, temperature of the reservoir near injection well dropped quickly to $60^{\circ} \mathrm{C}$ (injected water temperature). While the production processed, low temperature area expands to production well. After 20 years, production well maintains a temperature as high as $176^{\circ} \mathrm{C}$. On the other hand, in surrounding rock, temperature decreases only it is very-near injection well. The rest position is hardly affected by production process. For precise digital description of surrounding rock affected by injection well, we selected 6 points in surrounding rock as shown in Fig .1, and we examined their temperature during production processed within 20 years.
Fig .3 shows six points' time temperature change curve (A-F) in surrounding rock while the hot dry rock reservoir is exploited within 20 years. It can be seen from the diagram, only $20 \mathrm{~m}$ from injection well (point A and point D) is affected; 40m distance (point B and E) doesn't get affected within eight years; $100 \mathrm{~m}$ from injection well (point $\mathrm{C}$ and $\mathrm{F}$ ) is hardly affected within 20 years, and it has maintained a steady temperature $\left(200^{\circ} \mathrm{C}\right)$. 


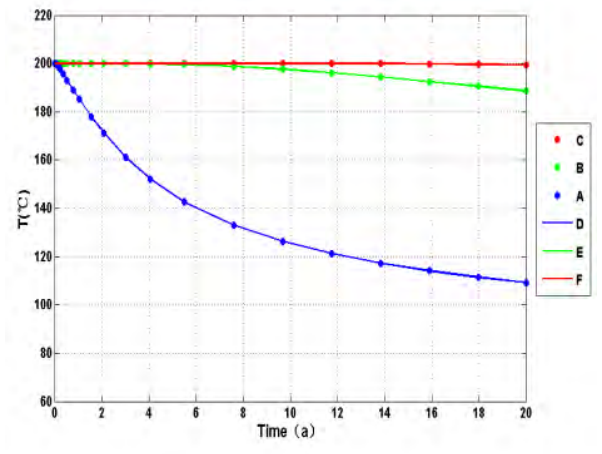

Figure 3. Temperature change of 6 dots in the surrounding rock during the 20 year period

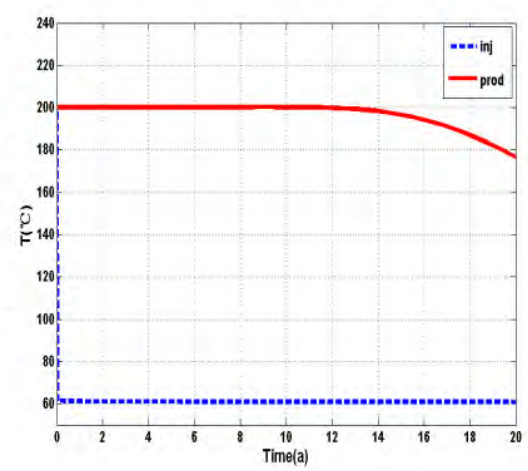

Figure 4. Temperature of Injection \& Production well

Fig .4 shows the temperature changes in Injection Well and Production Well. As we see, point near Injection Well is affected by injected water temperature, and it has remained $60^{\circ} \mathrm{C}$. Temperature of the production Well hold a high level, until 14 years later it decrease a little, but still as high as $176^{\circ} \mathrm{C}$.

\section{CONCLUSION}

Based on the follow model with three conditions: 1) the temperature of reservoir and surrounding rock are $200^{\circ} \mathrm{C}$, respectively; 2) surrounding rock is impermeable; 3 ) the water injection rate of well is $1.5 \mathrm{~kg} / \mathrm{s}$. The model simulation result demonstrates that:

1) The temperature of production well hold a high level for a long time, until 14 years later it will decrease a little, but still as high as $176^{\circ} \mathrm{C} 20$ years later.
2) The surrounding rock which is $20 \mathrm{~m}$ away from injection well is pretty affected; the measurement point which is $40 \mathrm{~m}$ away is little affected and it get a little decrease only 10 years later; the point away more than $100 \mathrm{~m}$ is hardly affected in 20 years while HDR production processed.

\section{REFERENCES}

[1] BARIA R, BAUMGARTNER J, GERARD A. Status of the European hot dry rock geothermal programmer [J].Geothermal Engineering, 1994, 19(1/2):33-48.

[2] PIERCE K G. An estimate of the cost of electricity production from hot dry rock [J]. Geothermal Resources Council Bulletin, 1993, (9): 197-203.

[3] Tester J W, Anderson B J, Batchelor A S, et al. Impact of enhanced geothermal systems on US energy supply in the twentyfirst century [J]. Philosophical Transactions of Royal Society, 2007, 365:1057-1094

[4] Brown D. The US hot dry rock program-20 years of experience in reservoir testing $[\mathrm{C}]$. Proceedings of World Geothermal Congress, Italy. $1995: 2607-2611$.

[5] Shi Xiaoqing, Zhang Keni, Wu Jichun. The history and application of TOUGH2 code[J]. Geotechnical Investigation \& Surveying.2009(10):29-34,39

[6] Pruess K, Oldenburg C, Moridis G. TOUGH2 User's Guide, Version 2.0[R]. Berkeley: Lawrence Berkeley National Laboratory, 1999

[7] Xu T, Pruess K. Modeling Multiphase Non-Isothermal Fluid Flow and Reactive Geochemical Transport in Variably Saturated Fractured Rocks 1: Methodology[J]. Americal Journal of Science,2 2001, 301:16-33

[8] Xu T, Sonnenthal E, Spycher N, et al. TOUGHREACT User's Guide: A Simulation Program for Non Isothermal Multiphase Reactive Geochemical Transport in Variably Saturated Geologic Media[R]. Berkeley: Lawrence Berkeley National Laboratory, 2005

[9] Xu Tianfu, Jin Guangrong, Yue Gaofan, et al. Subsurface Reactive Transport Modeling: A New Research Approach for Geo-ReSource and Environments[J]. Journal of Jilin University: Earth Science Edition, 2012, 42(5):1410-1425

[10] Yang Yanlin, Xu Tianfu, Li Jiaqi, Wang Fuguang. Complex Geological Body Modeling and Implementation of $\mathrm{CO} 2$ Geological Storage Simulation Using TOUGH[J]. Journal of Jilin University: Earth Science Edition, 2014,44(4):1307-1313

[11] Yu-Chao Zeng, Zheng Su, Neng-You Wu. Numerical simulation of heat production potential from hot dry rock by water circulating through two horizontal wells at Desert Peak geothermal field [J]Energy. 2013 92-107

[12] Tao Wenshuan. Numerical heat transfer [M]. Xi' an: Xi 'an jiaotong university press, 2001:156-214

[13] Xu Shizhe. The finite element method in geophysics [M]. Beijing: Science press, 1994

[14] Kong Xiangqian et al. The application of the finite element method in heat transfer [M]. Beijing: Science press, 1998, 09

[15] Huang Houcheng, Wang Qiuliang. Finite element analysis of heat conduction problems [M]. Beijing: Science press, 2011, 05 